\title{
A IMPERTINÊNCIA DO DISCURSO DO DIREITO PENAL JUVENIL À LUZ DA TEORIA GERAL DO GARANTISMO JURÍDICO DE FERRAJOLI: REFLEXÃO SOBRE AS TENDÊNCIAS SUBVERSIVAS DA PROPOSTA GARANTISTA
}

\author{
Vinícius de Moraes Franco ${ }^{1}$ \\ Vládia Maria de Moura Soares ${ }^{2}$
}

\section{RESUMO}

Este artigo busca analisar a adequação do Direito Penal Juvenil à luz das teorias garantistas de Ferrajoli. Para tanto, delinear-se-ão os elementos da Teoria Geral do Garantismo Jurídico para confrontá-la com o chamado Garantismo Penal Integral, filiado à lógica punitivista e à hipertrofia do Direito Penal. O desenvolvimento evolui para a análise da pertinência do Direito Penal Juvenil ao cotejá-lo com a legítima teoria garantista. Ao final, realizar-se-ão os apontamentos necessários acerca da inadequação do Direito Penal Juvenil, que segue a mesma lógica contraditória e expansionista do Direito Penal Integral.

Palavras-chave: Direito Constitucional da Criança e do Adolescente. Direito Infracional. Garantismo Penal Integral. Direitos fundamentais. Garantias constitucionais.

\section{THE IMPERTINENCE OF THE DISCOURSE OF JUVENILE CRIMINAL LAW IN THE LIGHT OF THE GENERAL THEORY OF LEGAL GUARANTEE BY FERRAJOLI: REFLECTION ON THE SUBVERSIVE TRENDS OF THE GUARANTEE PROPOSAL}

\begin{abstract}
This article seeks to analyze the adequacy of Juvenile Criminal Law in the light of Ferrajoli's guaranteeing theories. For that, will be outlined the elements of the General Theory of Legal Guarantee to confront it with the so-called Integral Penal Guarantee, affiliated to the punitivist logic and the hypertrophy of Criminal Law. Development has evolved into an analysis of the relevance of Juvenile Criminal Law by comparing it with the legitimate Guarantor Theory. At the end, the necessary notes will be made about the inadequacy of Juvenile Criminal Law, which follows the contradictory and expansionist logic as Integral Criminal Law.
\end{abstract}

Key words: Constitutional Law for Children and Adolescents. Infractional Law. Integral Penal Guarantee. Fundamental rights. Constitutional guarantees.

\section{INTRODUÇÃO}

\footnotetext{
1 Advogado. Professor voluntário da Faculdade de Direito da UFMT. Mestrando pelo Programa de PósGraduação em Direito da UFMT, na Linha de Pesquisa de Direitos Humanos e Fundamentais. vinimono@ outlook.com ou viniciusmfrancoadv@gmail.com .

${ }^{2}$ Advogada. Professora Adjunta de Criminologia e Direito Penal na Faculdade de Direito da UFMT. PósDoutoranda pela UFRGS. Doutora e Mestre em Direito do Estado pela PUC de SP. vss_adv34@ hotmail.com .
} 
Mesmo diante do inexpugnável panorama garantista do Direito Constitucional da Infância e Juventude, que determina o respeito às particularidades e especificidades da matéria socioeducativa e pressupondo um sistema normativo delimitado por princípios e finalidades específicas, destinado a responsabilizar da maneira mais apropriada o adolescente que comete ato infracional, surgem divergências doutrinárias acerca da natureza da medida socioeducativa, de modo que parte da doutrina passou a defender o posicionamento de que as medidas socioeducativas possuem uma natureza também retributiva. Cresce o número de partidários do entendimento de que a parte específica de atos infracionais do Direito da Criança e do Adolescente tem natureza penal e, portanto, deveria estar submetida aos princípios norteadores do sistema penal, recebendo a denominação de Direito Penal Juvenil.

As teorias do Garantismo Jurídico, com base no primado do direito penal mínimo, prezando pela excepcionalidade da restrição da liberdade e pela maximização dos princípios fundamentais, em consentâneo com os pressupostos da doutrina da Proteção Integral, são hábeis a expor equívocos interpretativos quanto aos direitos da criança e do adolescente, a partir das garantias constitucionais, de modo que se adota como marco teórico, desde logo, as teorias garantistas de Luigi Ferrajoli, que encontram expressão na sua mais importante obra, intitulada Direito e Razão, de 1989. Esses são os pressupostos teóricos iniciais que dão subsídios para confrontar a legitimidade do chamado Direito Penal Juvenil.

A ausência de consenso entre os operadores do Direito em geral acerca do tema demonstra que não foram percebidas todas as nuances do Direito Juvenil, enquanto ramo jurídico autônomo e dotado de normas especiais, sobretudo quanto à matéria socioeducativa, sendo então necessário investiga-lo sobre o enfoque da doutrina garantista. São pertinentes ou adequados os discursos do Direito Penal Juvenil na seara dos Direitos da Criança e do Adolescente? Que contribuições a Teoria do Garantismo Jurídico oferece à análise do Direito Penal Juvenil? Em que medida a legítima teoria garantista tem sido subvertida por novos discursos legitimadores da expansão do Direito Penal? Esses são questionamentos que procuramos responder neste estudo.

Em sede de metodologia de pesquisa em direito, Mezzaroba e Monteiro (2009, p. 50) definem "método como o caminho que adotamos para alcançar determinado fim". Dessa maneira, seleciona-se o método indutivo, em função da possibilidade de, a partir do objeto, “[...] pesquisar e identificar as partes de um fenômeno e colecioná-las de modo a ter uma percepção ou conclusão geral [...]” (PASOLD, 2007, p. 104). Presente também o raciocínio 


\section{A IMPERTINÊNCIA DO DISCURSO DO DIREITO PENAL JUVENIL À LUZ DA TEORIA GERAL DO GARANTISMO JURÍDICO DE FERRAJOLI: REFLEXÃO SOBRE AS TENDÊNCIAS SUBVERSIVAS DA \\ PROPOSTA GARANTISTA}

dedutivo, cujo protótipo é o silogismo, consistente numa construção lógica que, a partir de duas preposições chamadas premissas, retira uma terceira, nelas logicamente implicadas, denominada conclusão (GIL, 2008, pg. 9).

O presente artigo é de caráter qualitativo, tendo em vista que possui conteúdo descritivo e utilizará da análise bibliográfica como técnica de coleta de dados, pois se embasa em material já elaborado, constituído principalmente de livros e artigos científicos (GIL, 2008, pg. 44), que possibilitam a reflexão sobre uma teoria e o seu posterior cotejo para análise de um ramo jurídico específico.

Por essas razões, o que se discorrerá adiante segue em dois planos: no primeiro capítulo delinearemos os elementos da Teoria Geral do Garantismo, bem como, discorreremos sobre a subversão teórica do chamado Garantismo Penal Integral, filiado à lógica punitivista e à hipertrofia do Direito Penal, e, no segundo capítulo, analisaremos pertinência ou não de um Direito Penal Juvenil ao confronta-lo com a legítima teoria garantista.

\section{ELEMENTOS DA TEORIA GERAL DO GARANTISMO E A SUBVERSÃO TEÓRICA DO GARANTISMO PENAL INTEGRAL}

Na obra Direito e Razão de 1989 o jurista italiano Luigi Ferrajoli discorre sobre os contornos de uma teoria geral do garantismo jurídico, sendo que esse garantismo ultrapassa os limites do Direito Penal e se equipara a uma teoria geral de Direito, que pode, portanto, ser transportada a variados ramos da ciência jurídica, entre eles o Direito da Criança e do Adolescente.

O modelo garantista de Ferrajoli está fundado no respeito aos direitos fundamentais e nas garantias formalmente consagradas, entendidas como instrumentos para enfrentar a crescente divergência entre normatividade e eventuais equívocos interpretativos.

Norberto Bobbio prefacia a obra Direito e Razão e antecipa os fundamentos da aposta garantista ao se referir a ela como um "sistema geral do garantismo jurídico ou, se se quiser, a construção das colunas mestras do Estado de direito, que tem por fundamento e fim a tutela das liberdades do indivíduo frente às variadas formas de exercício arbitrário de poder" (FERRAJOLI, 1995, p. 7 - grifo nosso) 
Num cenário marcado pela falta de efetividade da normatização estatal, a concepção do garantismo é, em linhas gerais, a busca de uma melhor adequação dos acontecimentos do mundo empírico às prescrições normativas oficiais. (SILVA, 2015, p. 77)

[...] Propõe-se assim um modelo ideal de Estado de Direito, ao qual os diversos Estados Reais de Direito devem aproximar-se, sob pena de deslegitimação. Tem-se aqui então o aspecto propositivo da teoria, ao postular valores que necessariamente devem estar presentes enquanto finalidades a serem perseguidas pelo Estado de Direito, quais sejam a dignidade humana, a paz, a liberdade plena e a igualdade substancial (CADEMARTORI, 1999, p. 72).

Este modelo, para Ferrajoli, expressa um direito atento ao amoldamento da interpretação e da aplicação do Direito às prescrições constitucionais substanciais, ou seja, o modelo garantista estabelece que a produção e a interpretação do direito se dão vinculadas normativamente aos princípios e valores previstos nas constituições. Desse modo, Bobbio sustenta que nada vale a justificação racional e a declaração solene dos direitos fundamentais num ordenamento jurídico se dele não se extrai os meios para efetivação (garantia) desses direitos, por isso

(...) o problema que temos diante de nós não é filosófico, mas jurídico e, num sentido mais amplo, político. Não se trata de saber quais e quantos são esses direitos, qual é sua natureza e seu fundamento, (...), mas sim qual é o modo mais seguro para garanti-los, para impedir que, apesar das solenes declarações, eles sejam continuamente violados (BOBBIO, 2004, p. 95).

Para Mayara do Nascimento e Silva (2015, p. 80), Bobbio reconhece que o problema da eficácia dos direitos, sem dúvida, envolve necessariamente um debate sobre os limites do poder e passa por uma reformulação das noções de Estado, Direito e democracia, enquanto instrumentos de defesa do cidadão face ao arbítrio e à injustiça.

O garantismo como teoria geral do Direito pode ser compreendido sob alguns enfoques interligados. Num primeiro ângulo, garantismo designa um modelo normativo de Direito e caracteriza-se, no plano epistemológico, como um sistema cognoscitivo ou de poder mínimo; no plano político, como uma técnica de minimização da violência e maximização da liberdade e, no plano jurídico, como um conjunto de vínculos impostos ao poder punitivo do Estado em garantia dos direitos dos cidadãos. (FERRAJOLI, 2002, p. 684)

Assim, na compreensão garantista a legitimação do Estado Democrático de Direito se vincula a democracia material, na qual os direitos fundamentais devem ser respeitados, efetivados e garantidos, sob pena da deslegitimação paulatina das instituições estatais.

Portanto considera-se garantista aquele Estado Constitucional que prevê limites formais (forma e procedimento do processo legislativo) e, principalmente, substanciais 


\section{A IMPERTINÊNCIA DO DISCURSO DO DIREITO PENAL JUVENIL À LUZ DA TEORIA GERAL DO GARANTISMO JURÍDICO DE FERRAJOLI: REFLEXÃO SOBRE AS TENDÊNCIAS SUBVERSIVAS DA PROPOSTA GARANTISTA}

(conteúdo legal e interpretativo nos limites constitucionais) ao exercício dos poderes estatais. São os limites substanciais que impõem a funcionalização dos poderes do Estado a serviço das garantias dos direitos fundamentais dos cidadãos, a partir da proibição constitucional de lesionar os direitos e liberdades. Em outras palavras, o Estado garantista tem por objetivo o aumento dos direitos dos cidadãos, que se dá mediante "la maximización de las libertades y de las espectativas y en la minimización de los poderes." (FERRAJOLI, 1995, p. 866)

No Estado de Direito, onde as constituições estabelecem os direitos invioláveis dos cidadãos, cuja garantia é condição de validade substancial das normas por ele produzidas, o garantismo evidencia-se como uma doutrina jurídica de legitimação e, sobretudo, de perda de legitimação interna do direito. Portanto, é tarefa do jurista valorar as normas conforme os parâmetros substanciais da norma superior (FERRAJOLI, 1995, p. 874), ou seja, cabe ao jurista uma interpretação conforme a Constituição e os direitos fundamentais nela inseridos.

Como filosofia política, o garantismo exige do direito e do Estado a legitimação ou justificação externa (heteropoiese), em contraponto às doutrinas autopoiéticas.

As doutrinas heteropoiéticas, a exemplo do racionalismo iluminista, se estruturam no pressuposto de que o Estado e o Direito foram criados pelo homem para proteção dos seus próprios interesses vitais (FERRAJOLI, 1995, p. 881.). É dizer que o Estado e o Direito não são fins em si mesmo, tampouco exprimem valores intrínsecos, ao contrário, são apenas um meio legitimado com a finalidade de preservar e promover os direitos e garantias fundamentais dos indivíduos, sendo eles, os indivíduos, o fim do Estado e do Direito.

Para las doctrinas auto-poyéticas, el estado és um fin y encarna valores ético-
políticos de carácter supra-social y supra-individual a cuya conservación y
reforzamiento han de instrumentalizarse el derecho y los derechos. Para las doctrinas
hétero-poyéticas, por el contrario, el estado es um medio legitimado únicamente por
el fin de garantizar los derechos fundamentales de los ciudadanos, y políyicamente
ilegítimo si no los garantiza o, más aun, si el mismo los viola (FERRAJOLI, 1995,
p. 881).

O Estado Constitucional de Direito implica na rejeição do sistema autopoiético como o defendido por Luhmann, para o qual o fenômeno jurídico é um sistema fechado e autoreferencial $^{3}$, isento de trocas com o ambiente, de forma essas teorias muito se distanciam de qualquer propósito garantista.

\footnotetext{
${ }^{3}$ Mister informar que as propostas autopoiéticas caem como uma luva para tendências expansionistas do Direito Penal. Günther Jakobs assimila a teoria dos sistemas de Niklas Luhmann para a construção teórica de um Direito da normalidade, o "Direito Penal do Cidadão", entendido como prevenção geral positiva, em oposição a um outro Direito Penal, aquele destinado aos inimigos, caracterizado pela relativização de garantias penais e processuais. Trata-se do chamado "Direito Penal do Inimigo", que parte da premissa básica de que o Direito é
} 
Uma vez compreendido que a liberdade pessoal é uma garantia fundamental tutelada pelo Estado Democrático de Direito, denota-se que nele não há espaço para que se dê o avanço desmedido dos anseios punitivos. Mesmo assim, tem se tornado cada vez mais comum o uso do discurso das garantias constitucionais para justificar a ampliação do sistema penal. Um discurso teoricamente equivocado e ideologicamente subvertido vem ganhando adesão no meio científico, em certa medida, motivado pela convicção por parte de seus defensores de ser a resposta correta aos apelos sociais vigentes por justiça e maior rigor penal, a despeito dos limites constitucionais ao jus puniendi. Trata-se do que se tem chamado de Garantismo Penal Integral.

Para essas teses, o Garantismo Penal de Ferrajoli ignora o modelo constitucional, que adota um Estado Democrático de Direito e que, por seu turno, também tutela os direitos fundamentais de segunda e terceira dimensão. Assim, o Garantismo Penal Integral assimila um viés positivo que se propõe à tutelar a coletividade e a segurança pública, enquanto direito fundamental de segunda dimensão, essencial para a garantia da qualidade de vida da população. (BEDÊ JUNIOR; SENNA, 2009, p. 27).

O garantismo positivo, entendido como os deveres prestacionais do Estado Social, portanto, integraria, segundo aqueles que advogam por essa perspectiva, o garantismo penal integral. Assim, "Denominado de garantismo positivo, esse dever de proteção (no qual se inclui a segurança dos cidadãos) implica a obrigação de o Estado, nos casos em que for necessário, adequado e proporcional em sentido estrito, restringir direitos fundamentais individuais dos cidadãos." (FISCHER, 2010, p. 38 - grifos no original)

Trata-se, segundo eles, de mitigar direitos fundamentais para satisfazer outros, como manifestação de um dever de prestação do Estado que, em teoria, abandonou sua vocação arbitrária e violenta contra os cidadãos para assumir o status de Estado Social, em outras palavras, deixou a característica de inimigo do cidadão para se tornar um "amigo" que visa a realização do bem comum (BEDÊ JÚNIOR e SENNA, 2009, p. 25). Ora, a despeito da

um instrumento destinado a garantir a funcionalidade e a eficácia do sistema social e dos seus subsistemas, retirando qualquer substancialidade da ideia de bem jurídico-penal e qualquer dimensão axiológica. Para essa corrente muito baseada nas ideias de Luhmann, o bem jurídico-penal corresponde à necessidade de se proteger as expectativas normativas, e seus defensores, assumidamente, postulam que aquele indivíduo que viola o contrato social "perde todos os seus direitos como cidadão e como ser humano e passa a um estado de ausência completa de direitos" (JAKOBS, 2009, p. 24), em oposição a qualquer ideal garantista. Sobre isso, JAKOBS, Günther; MELIÁ, Manuel Cancio. Direito penal do inimigo: noções e críticas. Porto Alegre: Livraria do Advogado Editora, 2009 e MORAES, Alexandre Rocha Almeida de. A Terceira Velocidade do Direito Penal: o 'Direito penal do Inimigo'. Dissertação de Mestrado em Direito Penal/ Pontifícia Universidade Católica de São Paulo: São Paulo, 2006. 


\section{A IMPERTINÊNCIA DO DISCURSO DO DIREITO PENAL JUVENIL À LUZ DA TEORIA GERAL DO GARANTISMO JURÍDICO DE FERRAJOLI: REFLEXÃO SOBRE AS TENDÊNCIAS SUBVERSIVAS DA \\ PROPOSTA GARANTISTA}

discussão doutrinária suscitada, onde impera forte controvérsia, não se pode admitir a visão simplista dessas teses, que ignoram as diferenças entre normatividade e realidade, sobretudo ignorando - talvez deliberadamente - as distâncias entre as promessas do Estado Social "amigo" do cidadão e a efetividade delas, dentro daquilo que se convencionou chamar de "Constituição Simbólica"״ . É um fato que a simples existência de uma norma não implica na ordenação justa da sociedade e sobre isso são pertinentes as lições de Ana Paula Correa Sales (2012) ao apontar para um declínio do Estado de Bem-Estar Social, onde a intervenção estatal para equalizar as diferenças sociais e garantir as condições de vida digna a todos os indivíduos na sociedade míngua de maneira progressiva", e aí, "como forma de resolver os desafios lançados por esta conjuntura social se propõe um crescimento do Estado Penal como alternativa para a substituição do Estado Social.” Não parece aceitável, portanto, utilizar como base argumentativa um Estado Social pretensamente amigo que sequer se tornou realidade no mundo empírico. $\mathrm{O}$ garantismo surge exatamente como um modelo para dirimir a divergência entre a normatividade do modelo constitucional e a sua ausência de efetividade.

A inversão ideológica ao garantismo jurídico, como bem observado por Alexandre Bizzotto (2008), é marcada pela excessiva abstração teórica sobre a realidade, pela falta de um olhar social e valorativo para os problemas que aparecem, pela ausência de efetividade dos direitos humanos e pela fragmentação da ideia dos direitos humanos decorrente da complexidade social, além da ingênua confiança no ordenamento jurídico, todos esses fatores com o poder de permitir a naturalização da violação concreta aos direitos humanos.

Nessa perspectiva expansionista do Direito Penal, alheia aos problemas de efetividade da normatividade constitucional, se desenvolve a proposta do Garantismo Penal Integral, por vezes se contrapondo expressamente à legítima teoria garantista de Ferrajoli, e por outras vezes chegando ao absurdo de dizer que o sentido defendido pelo doutrinador italiano autoriza essa visão integral e, por consequência, que se flexibilizem direitos fundamentais em prol da segurança publica.

\footnotetext{
${ }^{4}$ Sobre a Constituição Simbólica, ver NEVES, Marcelo. A constitucionalização simbólica. 2. ed., São Paulo: WMF Martins Fontes, 2007.

${ }^{5}$ Mais impressões sobre a crise do Estado Democrático de Direito e dos direitos fundamentais, identificando uma profunda crise de efetividade e um sentimento generalizado de frustrações sobre as expectativas criadas pelo discurso constituinte, ver SARLET, Ingo Wolfgang. Constituição e proporcionalidade: o direito penal e os direitos fundamentais entre proibição de excesso e de insuficiência. Revista brasileira de ciências criminais. São Paulo: Editora Revista dos Tribunais, vol. 47, 2004, p. 60-122.
} 
O discurso do Garantismo Penal Integral é enfático ao afirmar que a maior efetividade da segurança dos cidadãos ou da coerção penal depende da limitação ou restrição de direitos fundamentais (BEDÊ JÚNIOR, Américo; SENNA, Gustavo, 2009, p. 24 e FISCHER, Douglas, p. 36 e 38), o que não é aceitável para qualquer teoria que se proponha garantista, revelando-se verdadeira aporia jurídico-hermenêutica.

Há um nítido descompasso entre a missão garantista dos direitos fundamentais e as interpretações tendentes à ampliação do poder punitivo. No sentido oposto do que pretende o chamado Garantismo Penal Integral, existem proibições constitucionais de lesionar os direitos e liberdades, sendo que muitas dessas proibições, como a prisão pena somente após trânsito em julgado de sentença criminal condenatória ${ }^{6}$, ou mesmo como a inimputabilidade penal etária, por exemplo, configuram, não princípios, mas verdadeiras regras no universo jurídiconormativo constitucional, não sujeitos, portanto, a ponderação ou sopesamento, e sim ensejando a obediência em sua totalidade e a interpretação e aplicação cabal e absoluta, mediante subsunção, de acordo com a dogmática alexyana.

Mesmo assim, esse tipo de discurso calcado no Garantismo Penal Integral e até mesmo no direito penal do inimigo vem ganhando expressividade no panorama jurisprudencial e acadêmico, talvez por ser o discurso mais agradável diante dos apelos da modernidade recente e de um sentimento de insegurança ontológica. ${ }^{7}$

Em coerente dissertação, BIZZOTTO (2008) aponta para o fato de que argumentos emocionais de cunho emergencial são utilizados para debilitar os parâmetros constitucionais, e os operadores do direito, ao estarem em contato direto com a realidade judicial, podem ser um dos primeiros a internalizar a violência estatal, com o manejo tímido dos instrumentos constitucionais disponíveis, ou mesmo manipulando-os contrariamente às finalidades de proteção aos direitos fundamentais.

Diversos fundamentos são utilizados para desvirtuar o espírito constitucional e mitigar direitos fundamentais, contrariando o aspecto propositivo da teoria garantista de

\footnotetext{
${ }^{6}$ Nesse sentido, Theodoro, Marcelo Antônio e FANAIA, Fernando Flores. A aplicação da teoria dos direitos fundamentais de Alexy na decisão do cumprimento antecipado da pena pelo Supremo Tribunal Federal. Revista Argumentum: Marília/SP, v. 19, n. 1, Jan.-Abr. 2018.

${ }^{7}$ Mais sobre os fenômenos da modernidade recente, como o aumento da criminalidade, do individualismo, bem como sobre o sentimento de insegurança ontológica e medo, gerando a expansão do Direito Penal, ver GIDDENS, Anthony. As Consequências da modernidade. São Paulo: Unesp, 1991, SILVA SÁNCHEZ, JesúsMaría. A Expansão do Direito Penal: Aspectos da política criminal nas sociedades pós-industriais. São Paulo: Revista dos Tribunais, 2002, BAUMAN, Zygmunt. Confiança e medo na cidade. Rio de Janeiro: Jorge Zahar, 2009 e YOUNG, jock. A Sociedade Excludente: exclusão social, criminalidade e diferença no modernidade recente. Rio de Janeiro: Revan, 2002.
} 


\section{A IMPERTINÊNCIA DO DISCURSO DO DIREITO PENAL JUVENIL À LUZ DA TEORIA GERAL DO GARANTISMO JURÍDICO DE FERRAJOLI: REFLEXÃO SOBRE AS TENDÊNCIAS SUBVERSIVAS DA PROPOSTA GARANTISTA}

Ferrajoli. Neste sentido, podem ser identificados nestas teorias expansionistas fatores que vão desde o "explícito confronto com as garantias constitucionais por meio da articulação de políticas legislativas com apoio midiático (movimentos da lei e ordem), passando pela justificação dogmática da problemática penal e redundando na tentativa de cooptação do ideário iluminista para justificar a ampliação punitiva.” (BIZZOTTO, 2008).

Sob o argumento de defender a sociedade, ideais autoritários como o garantismo penal integral foram racionalmente fortalecidos e, embora seus postulados tenham sido desqualificados pela criminologia crítica, eles permanecem muito presentes, motivo pelo qual assume-se neste ensaio, de forma contundente, a posição de defesa da necessidade de contenção do sistema penal por intermédio da aplicação efetiva das normas constitucionais, em observância aos fundamentos da autêntica teoria do garantismo jurídico.

A teoria garantista não admite que sejam formuladas proposições que, embora se afirmem garantistas, deixam concretamente a proteção dos direitos fundamentais contra o Estado Penal em segundo plano. Adotar esse tipo de posicionamente implica em descartar opções legitimamente garantistas enquanto parâmetros de racionalidade e de legitimidade da intervenção punitiva, critérios esses que se encontrarão desatendidos na prática, contrario sensu aos limites constitucionais, reduzindo a Constituição à mera fachada ideológica.

O modo mais seguro de garantir os direitos já enunciados constitucionalmente obviamente não pode ser pelo Direito Penal, mais drástica e ofensiva forma de intervenção estatal, circunscrito à condição de ultima ratio. Nesse sentido, a subversão ideológica do discurso garantista e a inadequada interpretação das finalidades das normas constitucionais de conteúdo garantidor para a ampliação do sistema penal constituem-se em modalidade de violência às pessoas.

Buscar garantir direitos sociais como a segurança e eficiência jurídica por meio de propostas que impliquem na expansão do direito penal e na flexibilização das garantias fundamentais, num Estado de Direito Constitucional (necessariamente também Social) que não logrou êxito em cumprir suas promessas, é incoerente teoricamente e dogmaticamente inadequado. Outrossim, qualquer tentativa de aumentar a competência punitiva do estado pressupõe que seja demonstrada a absoluta impossibilidade de alternativas não violentas, como políticas públicas de educação, emprego, cultura, lazer etc. (DIETER e SOUZA, 2015). 


\section{A IMPERTINÊNCIA DE UM DIREITO PENAL JUVENIL À LUZ DA LEGÍTIMA TEORIA GARANTISTA}

Ao adolescente que comete ato infracional é aplicada medida socioeducativa de caráter eminentemente pedagógico ${ }^{8}$, graças à ordem axiológica constitucional e infraconstitucional, sem olvidar as contribuições do panorama protetivo internacional, que adotam um sistema especial de proteção aos direitos fundamentais juvenis.

Não obstante, parte da doutrina passou a defender o posicionamento de que as medidas socioeducativas possuem uma natureza pedagógica e retributiva, causando uma cisão no campo científico: por um lado, estão aqueles que afirmam exclusivamente o caráter pedagógico da medida, defensores do Direito Infracional ${ }^{9}$, ao qual se filia este ensaio; por outro lado, estão aqueles que acreditam na natureza dúplice da medida, dando a ela características também retributivas, defensores do Direito Penal Juvenil.

Segundo esses últimos o Estatuto da Criança e do Adolescente teria estabelecido um mecanismo de punição de caráter pedagógico em sua concepção e conteúdo, mas retributivo em sua forma (SARAIVA, 2002, p. 48). Assim, defendem eles que a parte específica de atos infracionais do Direito da Infância e da Juventude tem natureza penal e, portanto, deveria estar submetida aos princípios norteadores do sistema penal, recebendo a denominação de Direito Penal Juvenil.

Esse pensamento afirma que as medidas socioeducativas "comportam aspectos de natureza coercitiva, vez que são punitivas aos infratores, e aspectos educativos" (VOLPI, 1997, p. 20). Fundamenta-se que o Direito Penal Juvenil é instituído pela norma estatutária e, ainda, ressalta que essa visão se fundamenta no garantismo penal e nos princípios de Direito Penal Mínimo (SARAIVA, 2002, p. 48).

O entendimento é de que as medidas socioeducativas possuem um caráter punitivo/retributivo similar à sanção penal, portanto, as disposições estatutárias sobre atos infracionais e as medidas representam uma subespécie de direito penal. Poderia ser entendido

\footnotetext{
${ }^{8}$ Dispõe o artigo 112 do Estatuto da Criança e do Adolescente que "Verificada a prática de ato infracional, a autoridade competente poderá aplicar ao adolescente as seguintes medidas: I - advertência; II - obrigação de reparar o dano; III - prestação de serviços à comunidade; IV - liberdade assistida; V - inserção em regime de semi-liberdade; VI - internação em estabelecimento educacional; VII - qualquer uma das previstas no art. 101, I a VI."

${ }_{9}^{9}$ Conosco, entre os defensores do Direito Infracional, estão: Alexandre Morais da Rosa, Paulo Afonso Garrido de Paula e Mário Luiz Ramidoff.
} 


\section{A IMPERTINÊNCIA DO DISCURSO DO DIREITO PENAL JUVENIL À LUZ DA TEORIA GERAL DO GARANTISMO JURÍDICO DE FERRAJOLI: REFLEXÃO SOBRE AS TENDÊNCIAS SUBVERSIVAS DA PROPOSTA GARANTISTA}

como um setor especializado da dogmática penal, através de um sistema positivo juvenil cuja finalidade seria a inserção dos princípios penais no sistema infracional.

Segundo essa corrente, o repúdio dos partidários do Direito Infracional às normas do Código Penal acaba, por vezes, suprimindo o gozo de garantias constitucionais e de princípios do Diploma Repressivo por parte dos adolescentes ${ }^{10}$, prejudicando seus interesses e sua proteção. Sustenta que negar tais benesses penais ao adolescente significa, além de irrazoabilidade - pois confere ao adolescente tratamento mais severo do que o dispensado ao adulto -, perceptível inconstitucionalidade. (FERRANDIN, 2008, p. 44)

Dito isso, a primeira reflexão necessária para revelar a impertinência do Direito Penal Juvenil circunda a natureza jurídica atribuída à medida socioeducativa. A Constituição Federal é clara em seu artigo 228 no que diz respeito à inimputabilidade penal etária dos menores de dezoito anos, cláusula pétrea da Carta Política, que consagra a responsabilidade penal diferenciada, prescrevendo que "São penalmente inimputáveis os menores de dezoito anos, sujeitos às normas da legislação especial". Tal prescrição fundamental reforça a norma do artigo 27 do Código Penal, que adota a presunção absoluta de inimputabilidade dos menores de dezoito anos e encontra eco no Estatuto da Criança e do Adolescente que, da mesma forma, declara a inimputabilidade dessa categoria, que passa a ser submetida, não às regras do Código Penal, mas à norma Estatutária, diga-se, especial.

A atual ordem constitucional reflete as seculares preocupações e aspirações sociais com o tratamento destinado à infância e à juventude, bem como busca a efetivação de seus direitos fundamentais. Fruto desses influxos, adota-se de forma clara e taxativa um sistema especial de proteção aos direitos fundamentais juvenis e, via de consequência, um sistema especial de responsabilização, que supera o espectro da indiferenciação ${ }^{11}$ do passado, a

\footnotetext{
${ }^{10}$ Nessa perspectiva, ver SARAIVA, João Batista Costa. As garantias processuais e o adolescente a que se atribua a prática de ato infracional. In: Justiça Adolescente e Ato Infracional: socioeducação e responsabilização. ILANUD; ABMO; SEDH; UNFPA (orgs). São Paulo: ILANUD, 2006.

${ }^{11}$ A infância e juventude, como hoje conhecemos, são construções da modernidade. Até os séculos XVII e XVIII a criança era apenas uma projeção do adulto, um objeto de indiferenciação, de forma que até então ela não era reconhecida como ser social, tampouco valorizada pela sua própria singularidade (SILVA, 2015, p. 14). Somente a partir do sec. XIX começa a ganhar força a valorização da infância pela sua singularidade, com características próprias, diferente dos adultos, tanto física como psicologicamente. Com relação ao termo adolescência, este surge no seguimento da delimitação do conceito de infância, sendo tal concepção construída enquanto fase distinta da infância e da fase adulta, ou seja, como uma fase de transição que encerra especificidades aos níveis físico e psíquico (SILVA, 2015, p. 19).
} 
doutrina penal do menor (sob a égide dos idos códigos penais de 1800) ${ }^{12}$, bem como a doutrina da situação irregular, normatizada pelo Código de Mello Mattos, de 1927, e pelo Código Menorista, instituído pela Lei n ${ }^{\circ} 6.697 / 79^{13}$. Esses modelos de responsabilização - aos quais é vedado retroceder - deram lugar ao paradigma da Proteção Integral, que opõe limites objetivos ao poder punitivo sobre adolescentes autores de ato infracional análogo a crime, em conformação com os artigos $227^{14}$ e 228 da CF/1988, dois dispositivos centrais para a constitucionalidade do novo direito que tomava forma e que deslegitima o velho Direito do Menor.

Fruto desse processo de constitucionalização do Direito Juvenil e diante da necessária reformulação da legislação especial infraconstitucional, o Estatuto da Criança e do Adolescente, de 1990, substituiu a ainda repressiva doutrina do Código de Menores de 1979 e instaurou em definitivo o paradigma da Proteção Integral, evitando que os preceitos constitucionais fossem reduzidos a meras intenções. Outrossim, “A Doutrina da Proteção Integral veio se contrapor às doutrinas anteriores, em que [...] a infância era um mero objeto de intervenção do Estado". (CUSTÓDIO; VERONESE, 2009, p. 68).

Na dicção de Karyna Batista Sposato (2013, p. 68)

A proteção integral deve ser concebida como a doutrina jurídica que sustenta todo atual Direito brasileiro da Criança e do Adolescente. Seu significado está em reconhecer que todos os dispositivos legais e normativos têm por finalidade proteger integralmente as crianças e os adolescentes em suas necessidades específicas, decorrentes da idade, de seu desenvolvimento e de circunstâncias materiais (grifo nosso)

Sobre a norma estatutária e sua consonância com o artigo 227 da Constituição de 1988, Saraiva (2003, p. 53) aduz que "neste dispositivo estão lançados os fundamentos do chamado Sistema Primário de Garantias, estabelecendo as diretrizes para uma Política Pública

\footnotetext{
${ }^{12}$ No Brasil, foi o Direito Penal que primeiro dispôs sobre a responsabilização infanto-juvenil pelos injustos praticados, de forma que "a doutrina penal do menor surgiu primeiro no Código Criminal de 1830, mantendo-se no Código Penal de 1890, ambos na vigência da Constituição Federal de 1824" (JESUS, 2006, p. 38). Sob a égide da doutrina penal do menor, o modelo de responsabilização "consistia em imputar a responsabilidade ao menor em função de seu entendimento quanto à prática de um ato criminoso" (PEREIRA, 2000, p. 11).

${ }^{13}$ Explica Veronese (1997, p. 10) que o Código de Menores de 1927 alterou e substituiu concepções obsoletas como as de discernimento, culpabilidade e responsabilidade, "disciplinando, ainda, que a assistência à infância deveria passar da esfera punitiva para a educacional". Esse Estatuto de Menores foi revogado pelo novo Código de Menores de 1979, cujo fator de destaque foi a consagração da "doutrina da situação irregular", pela qual as crianças e os adolescentes seriam objetos da norma quando se encontrassem em estado de "patologia jurídicosocial", seja pela situação de privação e de vulnerabilidade social, seja pela condição de vítima de violação de direitos, ou ainda pela prática infracional.

14 "Art. 227. É dever da família, da sociedade e do Estado assegurar à criança, ao adolescente e ao jovem, com absoluta prioridade, o direito à vida, à saúde, à alimentação, à educação, ao lazer, à profissionalização, à cultura, à dignidade, ao respeito, à liberdade e à convivência familiar e comunitária, além de colocá-los a salvo de toda forma de negligência, discriminação, exploração, violência, crueldade e opressão.”
} 


\section{A IMPERTINÊNCIA DO DISCURSO DO DIREITO PENAL JUVENIL À LUZ DA TEORIA GERAL DO GARANTISMO JURÍDICO DE FERRAJOLI: REFLEXÃO SOBRE AS TENDÊNCIAS SUBVERSIVAS DA PROPOSTA GARANTISTA}

que priorize crianças e adolescentes, reconhecidos em sua peculiar condição de pessoa em desenvolvimento."

Portanto, a inimputabilidade penal etária deve ser compreendida como um resultado do reconhecimento da condição peculiar de pessoa em desenvolvimento que caracteriza a criança e o adolescente, em consequência da incapacidade biopsicológica e social da pessoa menor de 18 anos para compreender a natureza criminal de seus atos ou para determinar seu comportamento conforme essa compreensão. Além disso, leva-se em conta que exatamente em decorrência do processo de desenvolvimento da sua personalidade, a aplicação de uma sanção de caráter penal, retributivo e coercitivo, com todas as suas consequências, só traria efeitos ainda piores a esse complexo e intenso processo de desenvolvimento.

À base da evolução histórico-jurídica nacional e internacional ${ }^{15}$, firmou-se o entendimento sobre a criança e o adolescente com particularidades, necessidades e, consequentemente, direitos específicos, e daí decorre a existência de diversos níveis de desenvolvimento e responsabilização. Não há que se falar em ausência de responsabilização sobre tal seguimento e sobre esse quadro e concepção, Mayara do Nascimento e Silva (2015, p. 59) explica que

O Direito Constitucional da Infância e Juventude concretizou mudanças na relação de responsabilidade existente entre crianças e adolescentes, Estado e sociedade civil; na forma de tratamento, eliminando preceitos prejudiciais originados da associação equivocada entre menor, crime e delinquiência. Portanto, a consideração da infância e adolescência como fase peculiar do desenvolvimento humano foi o princípio orientador para a construção de regras e normas jurídicas distintas do Direito Penal tradicional destinado aos adultos. Desta forma, o Direito Constitucional da Infância e Juventude reconheceu um sistema próprio de responsabilização para os menores de idade fundado em um modelo de responsabilidade diferenciado, em que o próprio legislador constitucional renuncia à imposição de uma pena criminal. (grifo nosso)

Prova da renúncia ao sistema penal, com base no melhor interesse da criança e do adolescente e não nos interesses retributivos da sociedade, é que é possível a aplicação ao

\footnotetext{
${ }^{15}$ No plano internacional, foi a Convenção dos Direitos da Criança, de 1989, que primeiro permitiu que se encarasse a criança como um ser titular de direitos e liberdades fundamentais. Com relação ao sistema de justiça e responsabilização da juventude, as Regras das Nações Unidas para a Proteção dos Menores Privados de Liberdade, de 14 de dezembro de 1990, têm como objetivo estabelecer normas mínimas para a proteção dos jovens privados de liberdade, para que esses sistemas de justiça sejam compatíveis com os direitos humanos e liberdades fundamentais. Ademais, fomentam o respeito, a segurança, o bem-estar físico e mental dos jovens, além de estabelecerem que a prisão de jovens deverá constituir uma medida de último recurso. Por sua vez, as Diretrizes das Nações Unidas para a Prevenção da Delinquência Juvenil, também de 1990, (Diretrizes de Riad), afirmam que o jovem não deve ser considerado como mero objeto de medidas de socialização e de controle (Princípio Fundamental 3), e as Regras de Beijing enunciam como uma das suas orientações fundamentais a promoção do bem-estar da criança e do adolescente, reduzindo a necessidade da intervenção legal, além de tratar de modo efetivo, equitativo e humano a situação de conflito com a lei (item 1.3).
} 
adolescente em conflito com a lei, a título de medida socioeducativa, quaisquer das medidas protetivas previstas no art. 101, I a VI, da Lei $\mathrm{n}^{\circ}$ 8.069/90, inclusive de maneira cumulativa. Assim, muitos são os casos de adolescentes autores de ato infracional com dependência química e essa situação demandará a inclusão do adolescente em programa de auxílio, orientação e tratamento a alcoólatras e toxicômanos, a despeito do ato infracional cometido.

Mesmo a medida de internação se distingue da pena privativa de liberdade imposta aos adultos pelo seu caráter pedagógico. A pena tem por finalidades a punição em si e o aspecto aflitivo ${ }^{16}$, por consequência, a prevenção de novos delitos, já as medidas socioeducativas, por sua vez, devem ser cumpridas em estabelecimentos apropriados, a partir de uma proposta de atendimento pedagógico individualizado e adequado a sua condição de pessoa em desenvolvimento, com o oferecimento de educação e profissionalização, obedecendo-se a rigorosa segregação por idade, compleição física e gravidade do ato.

Atesta de forma cabal o modelo de responsabilização especial e a natureza educativa da medida socioeducativa a criação do Sistema Nacional de Atendimento Socioeducativo SINASE instituído pela Lei $\mathrm{n}^{\circ} 12.594 / 2012$, que poderíamos chamar de uma lei de execução paras as medidas socioeducativas apta a regulamentar os programas de atendimento socioeducativo no Brasil. Notemos que a legislação especial relativa à criança e ao adolescente se especificou para a além do Estatuto da Criança e do Adolescente, a fim de dar concretude à mudança de paradigma que ocorreu.

O legislador, no exercício do poder representativo e majoritário, edita um modelo específico de execução que afirma o aspecto pedagógico do modelo de responsabilização adotado para adolescentes e prescreve como princípios do Sistema Nacional de Atendimento Socioeducativo: o respeito aos direitos humanos; a responsabilidade solidária da família, sociedade e Estado pela defesa dos direitos de crianças e adolescentes; o adolescente como pessoa em situação peculiar de desenvolvimento, sujeito de direitos e responsabilidades; a incolumidade, integridade física e segurança; o respeito à capacidade do adolescente de cumprir a medida; respeito à gravidade da infração e às necessidades pedagógicas do adolescente na escolha da medida, com preferência pelas que visem ao fortalecimento dos vínculos familiares e comunitários, entre outros.

\footnotetext{
${ }^{16}$ À guisa da Teoria Agnóstica da Pena, sem confrontar aqui com outras abordagens sobre a finalidade da pena, Salo de Carvalho (2002, p. 36) aduz que "entendida como fenômeno da política, a pena, assim como a guerra, não encontra sustentação no direito, pelo contrário, simboliza a própria negação do jurídico. Ambas (pena e guerra) se constituem através da potencialização da violência e da imposição incontrolada de dor e sofrimento".
} 


\title{
A IMPERTINÊNCIA DO DISCURSO DO DIREITO PENAL JUVENIL À LUZ DA TEORIA GERAL DO GARANTISMO JURÍDICO DE FERRAJOLI: REFLEXÃO SOBRE AS TENDÊNCIAS SUBVERSIVAS DA \\ PROPOSTA GARANTISTA
}

Data vênia, ao contrário do que afirma Emilio García Méndes (2006, p. 21), partidário do Direito Penal Juvenil, que aponta equívoco interpretativo ao buscar-se, segundo ele, a pretenção "tutelar" em uma lei "como el ECA claramente basada en el modelo de la responsabilidade", reafirmamos nossa crença num sistema de responsabilização juvenil, que de fato existe. Contudo, a verdadeira crise interpretativa se instala quando se pretende transportar esse modelo especial de responsabilização para o âmbito do Direito Penal, mitigando, de maneira antigarantista e inconstitucional, o caráter exclusivo da medida socioeducativa, que é a educação.

Outrossim, Mário Luiz Ramidoff, demonstra que não se pretende negar um sistema de responsabilização juvenil, mas sim que esse sistema se distancia das finalidades penais e que enxerga a medida socioeducativa enquanto resposta apta, adequada e própria à prática do ato infracional, que deve oferecer a emancipação do jovem, "possibilitando-lhe muito mais do que uma sadia formação da sua personalidade, mas, verdadeiramente, um projeto de vida responsável, ou seja, pelo qual se comprometa e responsabilize.” (RAMIDOFF, 2002, p. 77)

Ademais, os discursos do Direito Penal Juvenil representam verdadeira contradictio in terminis ao se justificar com base no Garantismo Jurídico de Ferrajoli e no Direito Penal Mínimo. Ou essas teses ignoram as reais bases garantistas ou se sustentam à guisa de um Direito Juvenil hermético e alheio à proteção integral e do adolescente.

\begin{abstract}
A lógica desenvolvida e utilizada para o reconhecimento de 'um modelo penal garantista' que se aplique na área jurídico-legal infanto-juvenil através do pretenso 'direito penal juvenil' é para não dizer o mais, no mínimo, contraditória em si, pois não se afigura razoável teórica, pragmática, discursiva e ou argumentativamente sustentar a minimização da incidência do direito penal, quando, precisamente, se propõe ampliar o seu âmbito de atuação ao direito da criança e do adolescente. (RAMIDOFF, 2007, p. 310 e 311)
\end{abstract}

A teoria do garantismo jurídico de Ferrajoli tem como um de seus princípios assegurar os direitos fundamentais dos cidadãos e, com esse fim, fornece instrumentos de limitação do poder estatal, prescrevendo a submissão e a adequação do sistema jurídico e da dogmática às condições formais e substanciais da Constituição da República. Ao contrário disso, os discursos do Direito Penal Juvenil seguem a mesma lógica contraditória e expansionista do Direito Penal Integral, à medida que subverte a ideologia garantista, constituindo-se em modalidade de violência aos adolescentes em conflito com a lei, seja porque o Direito Penal é o meio de intervenção estatal mais drástica, seja porque viola todo o arcabouço axiológico e substancial que sustenta o Direito da Criança e do Adolescente. 
Para que o Direito seja válido, é necessária sua conformação com aspectos formais e substanciais, que submetem sua elaboração, interpretação e aplicação às prescrições constitucionais, ou seja, no caso do Direito Juvenil, este se encontra em relação de obediência aos direitos fundamentais da criança e do adolescente em virtude do nível de juridicidade superior e vinculante conferido à Constituição, que prescrevem a inimputabilidade penal e um modelo de responsabilização especializado como regra de aplicação indelével e absoluta.

O Direito Penal Juvenil parece ver na seara Penal uma salvação, uma fonte de garantias ${ }^{17}$ para dar efetividade aos direitos fundamentais do adolescente que comete ato infracional, mas ignora que a eficácia dos direitos, segundo os postulados garantistas, envolve necessariamente um debate sobre os limites do poder. Nesse sentido, o garantismo designa um modelo normativo de Direito e caracteriza-se como um sistema cognoscitivo ou de poder mínimo, como uma técnica de minimização da violência e maximização da liberdade, além de um conjunto de vínculos impostos ao poder punitivo do Estado em garantia dos direitos dos cidadãos, de forma que o Direito Constitucional Juvenil estabelece proibições constitucionais de lesionar liberdades dos etariamente inimputáveis de maneira ilegítima.

Aparentemente bem intencionados, sustentam os detratores do Direito Infracional, que "o que não se pode permitir é que, minimizada a natureza retributiva/preventiva da medida sócio-educativa (e nesse caso penal), minimizem-se as garantias processuais e constitucionais, dando azo a um perverso discurso que permite a realização das mais bárbaras injustiças em nome do amor”. (SARAIVA, 2006, p. 182)

Tal apego ao Direito Penal como a melhor alternativa para efetivação dos direitos fundamentais juvenis é no mínimo suspeita, porque a utilização da lógica jurídico-penal, por seus traços repressivo-punitivos, certamente inverte o processo específico para apuração da responsabilização, bem como estabelece indevidamente uma outra discursividade que projeta legitimação à intervenção estatal através da permissibilidade de aplicação de medidas legais punitivas - senão, meramente retributivas. Assim, o adequado é que se desenvolva uma teoria jurídico-protetiva fundada nos valores constitucionais e estatutários, que realize uma "checagem" dos traços de um determinado processo interpretativo, "procurando, assim, eliminar toda categoria jurídica que não se coadune com a propedêutica socioeducativa, vale

\footnotetext{
${ }^{17}$ Sob esse pretexto, COSTA (2005, p. 161 e ss) acredita que "o reconhecimento da existência de um Direito Penal Juvenil contido no Estatuto tem por consequiência a identificação da necessidade de respeito às garantias processuais penais destinadas ao mesmo público, presentes no conjunto da legislação pátria", e advoga pela necessidade de reconhecimento da "natureza penal da legislação juvenil", pois só assim é possível considerar "todo o sistema correspondente de garantias constitucionais e de princípios aplicáveis de Direito Penal."
} 


\section{A IMPERTINÊNCIA DO DISCURSO DO DIREITO PENAL JUVENIL À LUZ DA TEORIA GERAL DO \\ GARANTISMO JURÍDICO DE FERRAJOLI: REFLEXÃO SOBRE AS TENDÊNCIAS SUBVERSIVAS DA \\ PROPOSTA GARANTISTA}

dizer, que 'não pode ser lido pelo sistema semântico, porque não tem significado' pedagógico, vale dizer, humanitário.” (RAMIDOFF, 2007, p. 306 e 307)

A responsabilização penal de adolescentes, pretensão do Direito Penal Juvenil, para Ramidoff (2007, p. 310), ainda que indiretamente pelo reconhecimento do caráter sancionatório das medidas legais socioeducativas, não pode ser outra coisa que não punição, vale dizer, exercício de violência legitimada, sobretudo pelo saber jurídico oficial - dogmática jurídico-penal - em oposição à ideologia garantista que busca a limitação do poder punitivo e maximização das liberdades individuais.

Nunca é demais lembrar as constatações de Carnelutti (1995, p. 45, 46 e 81) acerca dos processos destinados a atribuição de responsabilidade penal (punitiva), no sentido de que a "degeneração do processo penal é um dos sintomas mais graves da civilização em crise" e que "o processo por si mesmo é uma tortura." Continua o autor a descrever o processo penal afirmando que "As misérias do processo penal são aspectos da miséria fundamental do direito", e, por derradeiro, que "Não se trata de desvalorar o direito, mas de evitar que seja sobrevalorado".

O fato é que Direito Penal Juvenil em nada contribui para enfrentar o processo de crise de efetividade que o Direito Constitucional da Infância e Juventude apresenta, pelo contrário, traz como consequência inevitável um discurso criminalizante e punitivista, que esvazia o conteúdo valorativo e principiológico constitucional e estatutário, dando vasão a práticas retributivas que inflacionam a crise dos direitos fundamentais mediante a intervenção ilegítima e hipertrófica.

Além de atentar contra as teorias garantistas, a redução do Direito Infracional a uma espécie do Direito Penal é tanto ineficaz quanto também produz efeitos paradoxais, na medida em que parcela da sociedade e da comunidade jurídica, que sempre olhou o Direito Penal como última alternativa, agora quer fazer uso do mesmo para buscar uma solução para um problema estrutural e complexo, representado por criminalidade e sensação de impunidade (SILVA, 2015, p. 64), ao feitio do Garantismo Penal Integral e do Direito Penal do Inimigo.

A solução legítima para a efetivação dos direitos juvenis e para o oferecimento de todas as garantias processuais que lhes são devidas como sujeitos de direito não está no Direito Penal, mas dentro do próprio Direito Constitucional da Infância e Juventude - se preferir, Direito Juvenil, ou, ainda, Direito Infracional - como ramo jurídico autônomo, dotado de especificidades próprias e que, não por isso, exclui a influência de outras áreas do 
Direito e sua obediência aos valores constitucionalmente estabelecidos. Nesse sentido, leciona Guilherme de Souza Nucci (2016, p. 5) sobre o Direito da Criança e do Adolescente:

\begin{abstract}
não se trata de submatéria de Direito Civil, muito menos de Direito Penal. Da mesma forma que hoje se reconhece a autonomia do Direito de Execução Penal, embora contenha princípios comuns ao Direito Penal e ao Processo Penal, deve-se acatar a distinção do Direito da Infância e Juventude como regente de seus próprios passos, embora se servindo, igualmente, de princípios de outras áreas. Suas normas ladeiam o Direito Civil, servem-se dos Processos Civil e Penal, sugam o Direito Penal, adentram o Direito Administrativo e, sobretudo, coroam o Direito Constitucional. Mas são normas da Infância e Juventude, cujas peculiaridades são definidas neste Estatuto e, mais importante, consagradas pela Constituição Federal. (grifo nosso)
\end{abstract}

Não se pode admitir um Direito Penal Juvenil apenas pelo fato de que o Estatuto da Criança e do Adolescente tomou por base para a definição de atos infracionais as condutas enumeradas pelo legislador penal, por via de tipificação delegada e por questão de facilidade conceitual. Da mesma forma, por obvio, não é aceitável infligir tratamento prejudicial ao adolescente em conflito com a lei, negando-lhes garantias e benesses processuais que atendem ao imputável, apenas pelo fato de que não se reconhece o ato infracional e a medida socioeducativa como pertencentes ao universo penal.

Há que se esclarecer que garantias processuais não se confundem ou se restringem ao âmbito do processo penal, antes disso, pertencem ao nível constitucional, aproveitando aos variados ramos do Direito. O devido processo legal, a ampla defesa e o contraditório que, segundo alguns, são tão violados pela discricionariedade e pelo subjetivismo característico do Direito Infracional $^{18}$, vinculam-se à esfera constitucional (política) do Estado de Direito e não propriamente à esfera jurídico-penal (técnica), ou seja, são garantias constitucionais asseguradas à quaisquer pessoas que se encontrem numa relação jurídica processual.

Contribuindo mais uma vez com o entendimento aqui defendido, Ramidoff (RAMIDOFF, 2007, p. 312) assim leciona:

O devido processo legal, a ampla defesa e o contraditório enquanto garantias fundamentais preceituadas constitucionalmente, aqui, na área jurídico-protetiva da infância e da juventude também são recepcionadas segundo os matizes humanitários que levam em conta a condição peculiar de pessoas em desenvolvimento, senão, que reconhecidamente se tratam de sujeitos de direito.

\footnotetext{
${ }^{18}$ Sobre esse assunto, em defesa do Direito Penal Juvenil e afirmando que o Direito da Criança e do Adolescente é permeado de subjetivismos e discricionariedade por carecer de regulamentação processual ao direito material, FERRANDIN, Mauro. Princípio constitucional da proteção integral e direito penal juvenil: possibilidade e conveniência de aplicação dos princípios e garantias do direito penal aos procedimentos previstos no estatuto da Criança e do adolescente. Dissertação de Mestrado em Ciência Jurídica. UNIVALI. Itajaí: 2008, p. 42 a 52.
} 


\section{A IMPERTINÊNCIA DO DISCURSO DO DIREITO PENAL JUVENIL À LUZ DA TEORIA GERAL DO GARANTISMO JURÍDICO DE FERRAJOLI: REFLEXÃO SOBRE AS TENDÊNCIAS SUBVERSIVAS DA \\ PROPOSTA GARANTISTA}

Aliás, importante anotar, pois, que não configura anomalia jurídica a aplicação das garantias tipicamente penais em matéria infracional, bem ao contrário, significa a conjugação dos princípios garantistas, como limitadores da intervenção punitiva frente aos direitos fundamentais dos cidadãos, com a Proteção Integral e o Melhor Interesse do adolescente, conforme as imposições constitucionais. Significa reconhecer a absoluta finalidade pedagógica da medida socioeducativa e mesmo assim manejar todas as garantias penais possíveis para dirimir distâncias entre a normatividade constitucional e a efetividade dos direitos fundamentais, como suscita a o garantismo jurídico. É mister compreender que a ilusória facilidade metodológica oferecida pela analogia do Direito Penal Juvenil esconde a incontrolável possibilidade de criminalização, isto é, responsabilização penal do adolescente.

\section{CONCLUSÃO}

A Doutrina da Proteção Integral e o sistema especial de proteção que se inauguravam ensejaram novo paradigma no que tange ao modelo de responsabilização juvenil, de forma que cingiu seu objeto à reabilitação e à reintegração social do adolescente em conflito com a lei, bem como se distanciou do espectro da indiferenciação, da doutrina penal do menor e da situação irregular, opondo limites objetivos ao poder punitivo sobre adolescentes autores de ato infracional análogo a crime.

Ao longo deste trabalho buscamos tecer uma crítica às propostas do Direito Penal Juvenil no sentido de defendermos o caráter educativo da medida socioeducativa, que não possui caráter, essência ou mesmo conteúdo sancionatório, e de denunciar sua impertinência à luz do garantismo jurídico de Luigi Ferrajoli, compreendido como Teoria Geral do Direito que se alia ao compromisso de proteção constitucional aos direitos fundamentais da criança e do adolescente, à medida que designa um modelo normativo de Direito caracterizado por um sistema de poder mínimo, como uma técnica de minimização da violência estatal e maximização da liberdade. Assim, o Direito Constitucional da Criança e do Adolescente, de cunho garantista, estabelece limites e proibições constitucionais de lesionar direitos e liberdades dos etariamente inimputáveis de maneira ilegítima e, ao mesmo tempo, assegura que garantias constitucionais sejam aplicadas na seara infracional.

As pretensões expansionistas do Direito Penal Juvenil, em que pese a tentativa de se justificarem sobre as bases garantistas e de Direito Penal Mínimo, mostram-se deletérias para 
um sistema constitucional que aspira limitações ao jus puniendi e a maximização das liberdades individuais. Um verdadeiro contrassenso à luz da teoria do garantismo jurídico.

Conclui-se que os discursos do Direito Penal Juvenil seguem a mesma lógica contraditória e expansionista do Direito Penal Integral, à medida que subverte a ideologia garantista e promove a inadequada interpretação das finalidades das normas constitucionais de conteúdo garantidor para a ampliação do sistema penal, constituindo-se em modalidade de violência aos adolescentes em conflito com a lei, seja porque o Direito Penal é a modalidade de intervenção estatal mais drástica, seja porque viola todo o arcabouço axiológico e substancial que sustenta o Direito da Criança e do Adolescente.

\section{REFERÊNCIAS}

ALEXANDRE BIZZOTTO. A inversão ideológica do discurso garantista: a subversão da finalidade das normas constitucionais de conteúdo limitativo para a ampliação do sistema penal. Dissertação de Mestrado em Ciências Criminais. Pontifícia Universidade Católica do Rio Grande do Sul. Porto Alegre: 2008

BAUMAN, Zygmunt. Confiança e medo na cidade. Rio de Janeiro: Jorge Zahar, 2009

BEDÊ JÚNIOR, Américo; SENNA, Gustavo. Princípios do processo penal: entre o garantismo e a efetividade da sanção. São Paulo: Editora Revista dos Tribunais, 2009.

BOBBIO, Norberto. A era dos direitos. Rio de Janeiro: Elsevier, 2004.

CADEMARTORI, Sérgio. Estado de Direito e Legitimidade: uma abordagem garantista. Porto Alegre: Livraria do Advogado, 1999.

CARNELUTTI, Francesco. As misérias do processo penal. Trad. José Antonio Cardinalli. Campinas: Conan, 1995.

CARVAlHO, Salo de. Teoria Agnóstica da Pena. O modelo garantista da limitação do poder punitivo. In: CARVALHO, Salo de. Crítica à Execução Penal. Rio de Janeiro: Lumen Juris, 2002.

COSTA, Ana Paula Motta. As garantias processuais e o direito penal juvenil: como limite na aplicação da medida sócio-educativa de internação. Porto Alegre: Livraria do Advogado, 2005.

CUSTÓDIO, André Viana; VERONESE, Josiane Rose Petry. Crianças esquecidas: o trabalho infantil doméstico no Brasil. Curitiba: Multidéia, 2009. 
DIETER, Mauricio Stegemann; SOUZA, Luciano Anderson. Irracionalismo e redução da maioridade penal. IBCCRIM, boletim 271, junho de 2015. Disponível em: $<$ https://www.ibccrim.org.br/boletim_artigo/5441-Irracionalismo-e-reducao-daaioridadepenal>. Acesso em: 14 de agosto de 2018.

FERRAJOLI, Luigi. Derecho y razón. Teoría del garantismo penal. Madrid: Trotta, 1995.

Direito e razão: teoria do garantismo penal. São Paulo: Editora Revista dos Tribunais, 2002.

FERRANDIN, Mauro. Princípio constitucional da proteção integral e direito penal juvenil: possibilidade e conveniência de aplicação dos princípios e garantias do direito penal aos procedimentos previstos no estatuto da Criança e do adolescente. Dissertação de Mestrado em Ciência Jurídica. Universidade do Vale do Itajaí/UNIVALI. Itajaí: 2008.

FISCHER, Douglas. O que é garantismo penal (integral). In: CALABRICH, Bruno; FISCHER, Douglas; PELELLA, Eduardo. Garantismo penal integral: questões penais e processuais, criminalidade moderna e a aplicação do modelo garantista no Brasil. Salvador: Editora JusPODIVUM, 2010, p. 25 a 50.

GIDDENS, Anthony. As Consequências da modernidade. São Paulo: Unesp, 1991.

GIL, Antonio Carlos. Como elaborar projetos de pesquisa. 4. ed. São Paulo: Atlas, 2008.

JAKOBS, Günther; MELIÁ, Manuel Cancio. Direito penal do inimigo: noções e críticas. Porto Alegre: Livraria do Advogado Editora, 2009.

JESUS, Maurício Neves. Adolescente em conflito com a lei: prevenção e proteção integral. Campinas: Savanda, 2006, p. 38.

MÉNDES, Emilio García. Evolución historica del derecho de la infancia: ¿Por que una historia de los derechos de la infancia? In: Justiça Adolescente e Ato Infracional: socioeducação e responsabilização. ILANUD; ABMO; SEDH; UNFPA (orgs). São Paulo: ILANUD, 2006.

MEZZAROBA, Orides; MONTEIRO, Cláudia Servilha. Manual de Metodologia da Pesquisa no Direito. 5 ed. São Paulo: Saraiva, 2009.

MORAES, Alexandre Rocha Almeida de. A Terceira Velocidade do Direito Penal: o 'Direito penal do Inimigo'. Dissertação de Mestrado em Direito Penal. Pontifícia Universidade Católica de São Paulo: São Paulo, 2006.

NEVES, Marcelo. A constitucionalização simbólica. 2. ed., São Paulo: WMF Martins Fontes, 2007.

NUCCI, Guilherme de Souza. Estatuto da Criança e do Adolescente Comentado. Rio de Janeiro: Forense, 2016.

Rev. de Criminologias e Políticas Criminais | e-ISSN: 2526-0065 | Evento Virtual | v. 6 | n. 1 |

p. 1-23 | Jan/Jun. 2020 
PASOLD, Cesar Luis. Prática da Pesquisa jurídica e Metodologia da pesquisa jurídica. 10 ed. Florianópolis: OAB-SC editora, 2007.

PEREIRA, Tânia da Silva. O melhor interesse da criança: um debate interdisciplinar. Rio de Janeiro/São Paulo: Renovar, 2000.

RAMIDOFF, Mário Luiz. Direito da Criança e do Adolescente: por uma propedêutica jurídico-protetiva transdisciplinar. Tese de Doutorado em Direito. Universidade Federal do Paraná: 2007.

Lições de direito da criança e do adolescente. 2. tir. Curitiba: Juruá, 2006.

O ato Infracional: por um compromisso com o futuro. In: Espaço Jurídico. Ano 3, n. 6. São Miguel do Oeste: Arcus, 2002.

SALES, Ana Paula Correa. A criminalização da juventude pobre no Brasil e a ascensão de um Estado de Direito Penal Máximo. Tese de Doutorado apresentada ao Programa de Doutorado em "Pasado y Presente de los Derechos Humanos" da Universidad de Salamanca: Salamanca: 2012.

SARAIVA, João Batista Costa. Adolescente em conflito com a lei. Da indiferença à proteção integral - uma abordagem sobre a responsabilidade penal juvenil. Porto Alegre: Livraria do Advogado, 2003.

As garantias processuais e o adolescente a que se atribua a prática de ato infracional. In: Justiça Adolescente e Ato Infracional: socioeducação e responsabilização. ILANUD; ABMO; SEDH; UNFPA (orgs). São Paulo: ILANUD, 2006

Desconstruindo o mito da impunidade. Brasília: Saraiva, 2002.

SARLET, Ingo Wolfgang. Constituição e proporcionalidade: o direito penal e os direitos fundamentais entre proibição de excesso e de insuficiência. In: Revista brasileira de ciências criminais. São Paulo: Editora Revista dos Tribunais, vol. 47, 2004.

SILVA SÁnCHEZ, Jesús-María. A Expansão do Direito Penal: Aspectos da política criminal nas sociedades pós-industriais. São Paulo: Revista dos Tribunais, 2002.

SILVA, Mayara do Nascimento e. A transposição teórica do garantismo jurídico para o Direito Constitucional da Infância e Juventude. Dissertação de Mestrado em Ciências Jurídicas. Universidade Federal da Paraíba. João Pessoa: 2015.

SPOSATO, Karyna Batista. Direito penal de adolescentes: elementos para uma teoria garantista. São Paulo: Saraiva, 2013.

VERONESE, Josiane Rose Petry. Temas de direito da criança e do adolescente. São Paulo: LTr, 1997. 
VOLPI, Mário. O adolescente e o ato infracional (org). São Paulo: Cortez, 1997.

YOUNG, Jock. A Sociedade Excludente: exclusão social, criminalidade e diferença no modernidade recente. Rio de Janeiro: Revan, 2002. 